\title{
Transnational Education through Engagement: Students' Perspective
}

\author{
Iwona Miliszewska, John Horwood and Albert McGill \\ Victoria University, Melbourne City, Australia
}

Iwona.Miliszewska@vu.edu.au

\begin{abstract}
A Computer Science degree is offered by Victoria University both locally in Australia and transnationally in Hong Kong. The degree includes a compulsory final year project subject. The project, a team effort, involves the design and implementation of a real life computer application for an external client. The project model in Hong Kong was modified to accommodate a variety of time, distance, and cultural constraints, but its core components of group context, project-based problems, and outside focus remained unchanged. Australian teachers responsible for the program consider these three project components essential to transforming computing students into competent graduates. Do Hong Kong students support this view? This paper reports on a study of the students' perceptions of the project experience and the relative importance of its three components. The paper concludes by considering the implications of the study on the project model.
\end{abstract}

Keywords : transnational education, engagement theory, cultural constraints, project model

\section{Introduction}

Transnational education refers to the delivery of distance education to students in a country different from that of the offering institution. Victoria University offers a transnational computer science degree in Hong Kong. The challenge is to provide a credentialed qualification that also offers students a meaningful learning environment. This challenge is compounded by the fact that the degree is required to be identical to that offered by the university in Australia, while at the same time meeting the expectations of students in both locales.

The degree program involves a Project subject, which utilizes the knowledge gained throughout the program to develop a real-life computer system. Project is designed to consolidate existing knowledge, and to empower students through engagement with a genuine work environment; it is an integral part of the computer science degree. Most subjects of the transnational degree are taught with the aid of part-time Hong Kong lecturers; however the Project, regarded as critical to the quality of the degree, is conducted by Melbourne lecturers in distance education mode. Opinions on the matter of adaptability of transnational programs are divided. Some argue that those programs should be tailored to the specific cultural context of the students (Kelly \& Tak, 1998); others claim that cultural differences can be overcome be applying universal principles of good teaching regardless of where the program is taught (Biggs, 1997).

Material published as part of these proceedings, either on-line or in print, is copyrighted by Informing Science. Permission to make digital or paper copy of part or all of these works for personal or classroom use is granted without fee provided that the copies are not made or distributed for profit or commercial advantage AND that copies 1) bear this notice in full and 2) give the full citation on the first page. It is permissible to abstract these works so long as credit is given. To copy in all other cases or to republish or to post on a server or to redistribute to lists requires specific permission from the publisher at Publisher@InformingScience.org
A distance education mode of delivery notwithstanding, a transplant of the Project model used in Melbourne proved impossible given the different constraints of the transnational context; a unique transmational Project model had to be de veloped

The Project model represents a particular approach to teaching and learning, considered most effective by Australian teachers, and highly ap- 


\section{Transnational Education through Engagement}

preciated by Australian students. Given the changed requirements and additional constraints imposed by the transnational context, it was important to discover if the Project model was equally regarded by Hong Kong students. This paper reports on the results of a survey that has been conducted to seek Hong Kong student perceptions of the Project model.

\section{Rationale behind the Project}

The aim of the Project is to provide students with an opportunity to work on a real-life software development project; to appreciate the needs of the business client for whom they are expected to build the software system; to apply software engineering and database design methodologies to the design and implementation of a complete system; to confront issues developers face on a daily basis, such as liaison with clients, working in a team, documenting the project; to gain experience in translating their knowledge into practice; and to obtain feedback concerning their progress from intensive reviews of their work. Project is based on three conceptual frameworks for learning and teaching.

\section{Problem Based Learning}

Firstly, the Project promotes Problem Based Learning (PBL). Many variations of PBL have been documented, but all of them include situations where an initial problem serves as a catalyst for subsequent learning (Fogarty, 1997; Kingsland, 1996). The learning that occurs in working with the problem enables students to develop new knowledge, as well as further consolidate their existing skills and knowledge (Schiller, Ostwald \& Chen, 1994). Students have a greater respons ibility for their own learning and receive less guidance from the teacher, factors distinguishing PBL from subject-based learning (Dolmans, 1992). The role of the teacher is different too: it is one of consultant rather than instructor. PBL usually includes a collaborative component; students often work in groups where collective decisions are made about task distribution, and where group members investigate different aspects of the problem that together contribute to the total solution.

\section{Engagement Theory}

Secondly, in addition to PBL in a collaborative environment, Project advocates the pursuit of worthwhile projects, that is, real projects commissioned by real clients. The emphasis on 'authentic' tasks, PBL, and collaboration exemplify the three components of another framework for learning - Engagement Theory. The major premise of engagement theory is that students must be engaged in their course work in order for effective learning to occur. The theory posits three primary means to accomplish engagement: (1) an emphasis on collaborative efforts, (2) project-based assignments, and (3) nonacademic focus. It is suggested that these three methods result in learning that is creative, meaningful, and authentic (Kearsley \& Schneiderman, 1999). Engagement theory is based on the idea of creating successful collaborative teams that work on tasks that are meaningful to someone outside the classroom. Its core principles are summarized as "Relate", which emphasizes characteristics such as communication and social skills that are involved in team effort; "Create", which regards learning as a creative, purposeful activity; and "Donate", which encourages learners to position their learning in terms of wider community involvement. To this end, Project presents itself as a perfect example of a real life application of engagement theory.

\section{Capstones}

Thirdly, the Project is the final and all-encompassing subject in the degree program. It is a culminating experience in which students synthesize and consolidate knowledge acquired throughout their studies. Fairchild \& Taylor (2000) define such experience as a Capstone. In addition to integration, experiential learning, and real-world problem solving, capstone emphasizes teamwork, decision- making, critical thinking, and interpersonal communication. These are non-technical skills considered essential in many 
types of work, and computing work is no exception; graduates are expected to demonstrate technical skills, as well as project management skills and awareness of business practices (Fairchild \& Taylor, 2000; Magney, 1996; Novitzki, 1998).

\section{The Local Project Model}

Guided by the three frameworks presented above, Project was included as a mandatory subject in the computer science degree to enable students to consolidate the knowledge and skills gained throughout the degree. As a consequence, an elaborate system of project supervision exists to support Melbourne students. Students are divided into groups; each group is allocated an industry project and an academic supervisor. The project is sourced, by the Project coordinator, from local business and industry, and typically is an application, of interest to the client, which does not require immediate implementation. Although the problem is situated in the 'real-world', the pressure on the students for successful completion is minimized. Thus, students are able to concentrate on the problem in hand. They can proceed at a pace that enables them to gain maximum benefit from the experience, and complete work that is of high standard. The groups meet with their supervisor on a regular basis and review progress, but major responsibility for project completion rests with the students. Despite some minor problems, Project has proved a very success ful vehicle in bridging the transition from the theoretical or restricted knowledge of the classroom to the broader environment of the workplace (Churcher \& Cockburn, 1997). It has also proved very appealing to prospective employers.

\section{The Transnational Project Model}

\section{Constraints and Concerns}

The Hong Kong Project model had to satisfy two major constraints associated with transnational programs: the quality constraint and the authenticity constraint. The quality constraint required that the Project meet quality assurance criteria of Victoria University, as well as the quality assurance body in Hong Kong; the authenticity constraint required that the transnational model should not differ significantly from the one provided in Melbourne. These constraints sparked concerns, as it soon became apparent that transplanting the Melbourne Project model into the Hong Kong setting without any modifications would not be possible. Should the model be, and to what extent could it be, modified without compromising the authenticity constraint? Would the quality of the Project be preserved?

In 2001 the Hong Kong government provided the opportunity for non-local programs to seek official accreditation. In response to this offer the program quality control procedures were reviewed to ensure that they satisfied both the university requirements and the Hong Kong accreditation criteria. In fulfilling both the legislative and administrative requirements, the accreditation process provided an opportunity to review the quality of the course from a transnational perspective; it confirmed the importance of maintaining and continually evaluating the existing quality control procedures.

During the meetings with the Accreditation Committee, Project became a point of contention. The academic members of the committee were concerned that the Hong Kong educational sys tem may not have equipped students with the independent study skills required to complete this subject. The committee stopped short of recommending that Project be restricted to a laboratory exercise although it suggested appointment of a part-time Hong Kong lecturer to assist students on a day-to-day basis.

Another issue related to cultural factors was the sourcing of potential projects in Hong Kong. The Project coordinator was not resident in Hong Kong, had no intimate knowledge of the business and industrial environment, and did not possess the language skills to negotiate with prospective clients. It was clear that a model that was different from the home approach would be needed in Hong Kong. 


\section{Implementation}

In Project, the teacher-student interaction is structured around the development of software to solve an industry problem. Academic project coordinators play a mentoring rather than an instructional role, and the Project model accommodates this different mode of teaching. The barrier of distance excluded replication of the model used in Australia and, as a result, a hybrid solution incorporating both distance and traditional educational methods was adopted (Dede, 1996). This solution made use of the Internet and electronic communication, but not to the exclusion of the face-to-face contact.

The Project model architecture is a three-tier one: the organizational tier details the administrative structure and communication procedures, the technological tier specifies the media and tools to support the organizational tier, and the quality tier ensures that the overall Project model meets the accepted standards of quality distance education.

\section{Organization}

Comprehensive Project Guidelines specify all project requirements, identify milestones and deadlines, and describe assessment. The Project is conducted over a six-month period each year. Students organize themselves into groups, and each group finds a project supported by a sponsor (client) from the local industry. The Project is divided into three stages; individual project groups submit reports and meet with the project coordinator at each stage. The face-to-face meetings with individual groups facilitate resolution of problems that could not be addressed adequately in a general manner, or solely in written mode (Bullock, 1998). During the final meeting students demonstrate their systems. Grades are awarded on project reports and software demonstration, while feedback on progress is provided throughout.

\section{Technology}

The Internet is used for submission of project documentation. A system, using Java, Web browsers and JavaScript was developed to facilitate the se submissions. Its major components comprise a Web browser user interface and a client-server application written in Java. In addition, Project Web site, Project Discussion Room, and electronic mail are used extensively for individual, group, and global communication. Access to the University library is also provided through the Internet, as is an index cataloguing public domain and free software, Standards groups Web sites, and research material.

\section{Quality}

The quality mechanism ensuring the academic validity of the Project and its equivalence to the Australian offering has two perspectives: institutional and educational. As an institution, the University has developed regulations and guidelines to which any offshore program must adhere, and the Project is no exception. The Academic Board is particularly concerned with academic matters, including teaching arrangements, resources and assessment. Educationally, academics responsible for the Project must guarantee its quality. To this end, the Project model reflects the universal seven principles for good practice in undergraduate education (Chickering \& Gamson, 1987; Chickering \& Ehrmann, 1996).

\section{Project as Engagement}

Project is structured around the key components of engagement theory - Relate, Create and Donate. Students are divided into groups (relate); and each group is responsible for sourcing an industry project (create) that is important to a local business (donate).

\section{Relate}

To best imitate the real-life software development environment, students work on their projects in groups of three or four students. This not only exposes them to teamwork, but also to projects that are 
more substantial. Students are expected to form their own project groups. This results in few reports of interaction problems and gives students a chance to effectively pool their expertise. A project is usually of better quality if the project group is composed of a database 'expert', a Graphical User Interface developer, a CASE tool practitioner and a person experienced in software documentation. This differentiation of tasks is better negotiated within compatible groups. All students contribute to each stage of the project and thus gain experience in all aspects of software development, in the process developing interpersonal relationships and collaborative skills.

\section{Create}

The Project typically involves a problem situated in the 'real world', and requires the development of a computer system. Students engage in the creative process by analyzing the problem, developing a system design, and implementing it. However, the pressure on the students for successful completion in a restricted time-frame is minimized. Thus, students are able to concentrate on the problem in hand. They can proceed at a pace that enables them to gain maximum benefit from the experience, and complete work that is of high standard.

\section{Donate}

While working on the Project, students interact with real-world clients and solve real-world 'big' problems. The responsibility of finding a client and a project rests with the students. The advantage of this approach is threefold. Firstly, the students gain an experience of computing 'in the large'. Secondly, they interact with their clients in a similar manner to software developers. Thirdly, the students see their software systems deployed in actual organizations thereby gaining a sense of satisfaction and confidence in their skills. Students usually choose their projects in the area of business or commercial applications although sometimes they develop software for their local church or social club.

\section{Is Learning by Engagement the Ideal Model for All?}

The Project represents and promotes the philosophy of Problem Based Learning, Engagement Theory and the Capstone paradigm. Academics consider it an essential ingredient of the computer science course and, following the philosophy of Informing Science, consider it the best way to optimize students' learning experience, i.e. inform clients (Cohen, 1999). Although well intended, this approach is based on one important assumption, namely that the students too regard it a valuable learning experience.

One concern was that students, used to teacher-centered approaches, might not accept the idea of selfdirected project work. Research suggests that students faced with this type of work may feel doubtful about its value, particularly if they have been accustomed to teacher-centered approaches (Felder \& Brent, 1996). However, research also indicates that students usually have greater motivation to learn in the context of solving a problem than if the content is delivered out of context (Idrus, 1993; Schiller et al. 1994). Furthermore, Schiller et al. (1994) reported that students believed that their ultimate goals, including career prospects, would be better met by problem-based rather than subject-based learning.

Although the Hong Kong project model accommodates a variety of differences and constraints dictated by time, distance and culture, its core premise of self-directed project-based learning appears to be at odds with the generally held perceptions of Chinese learners. Firstly, Chinese education has been characterized as 'firmly based on knowledge transmission with a single curriculum (often a single textbook). Making the curriculum relevant to everyday life has low priority' (Robinson, 1998, p.371). The Project's emphasis on real-life context did not seem important. Secondly, Chinese students are perceived to be passive learners, used to a very teacher-centered learning, with the teacher seen as the source of information and 'success in learning often seen as the reproduction of what the teacher has taught' (Robinson, 1998, p.371). Emphasis has trad itionally been on the content of a centrally controlled curriculum rather 


\section{Transnational Education through Engagement}

than on thinking skills and learning processes. Thus, students were likely to have deve loped learning styles that might be at odds with the student-directed, enquiring and challenging nature of Project.

In Hong Kong, time is a massive constraint to teaching and learning. Time constraints are particularly evident for part-time students, especially if they are in full-time employment and trying to cover maximum amount of study requirements in the minimum amount of time. However, it is essential that stur dents should devote time to discussion, reflection, and search for resources, in order to clarify the Project problem. Would the pressure of time detract from the meaningful learning that Project has been designed to encourage?

Given the discrepancies between the nature of the Project and the acknowledged constraints on the Hong Kong student, it is understandable that questions arose regarding the students' acceptance of the Project. However, there was also evidence to suggest that many of the characteristics of the Chinese learner described above may depend on teaching practices, and that Chinese students could adapt quite easily to student-centered approaches if they were in learning environments that encourage them to do so (Kember \& Gow, 1991; Kember, 1998). Since Project is regarded as critical to the completion of the degree program, a survey was conducted to seek the views of Hong Kong students on the importance of the characteristics of the Project model, and the relative importance of its three components: group context, project-based task, and outside focus.

\begin{tabular}{|c|c|c|c|c|c|}
\hline Group Context & 5 & 4 & 3 & 2 & 1 \\
\hline $\begin{array}{l}\text { Improved my communication, planning, } \\
\text { and management skills. }\end{array}$ & $44 \%$ & $53 \%$ & $3 \%$ & & \\
\hline $\begin{array}{l}\text { Forced me to clarify and describe prob- } \\
\text { lems, thereby facilitating solutions. }\end{array}$ & $42 \%$ & $52 \%$ & $6 \%$ & & \\
\hline $\begin{array}{l}\text { Helped me understand and accept the per- } \\
\text { spectives of fellow group members. }\end{array}$ & $41 \%$ & $53 \%$ & $6 \%$ & & \\
\hline Project-based Task & 5 & 4 & 3 & 2 & 1 \\
\hline $\begin{array}{l}\text { Made me apply my knowledge and ideas } \\
\text { to a specific task. }\end{array}$ & $43 \%$ & $54 \%$ & $3 \%$ & & \\
\hline $\begin{array}{l}\text { Was more interesting than working on } \\
\text { tutorial exe rcises. }\end{array}$ & $41 \%$ & $55 \%$ & $4 \%$ & & \\
\hline $\begin{array}{l}\text { Gave me a sense of control of my learn- } \\
\text { ing. }\end{array}$ & $44 \%$ & $50 \%$ & $6 \%$ & & \\
\hline Outside Focus & 5 & 4 & 3 & 2 & 1 \\
\hline Increased my motivation for work. & $26 \%$ & $62 \%$ & $11 \%$ & $1 \%$ & \\
\hline $\begin{array}{l}\text { Taught me skills associated with client } \\
\text { interaction and customer service. }\end{array}$ & $30 \%$ & $64 \%$ & $6 \%$ & & \\
\hline $\begin{array}{l}\text { Was more satisfying than working on a } \\
\text { textbook problem. }\end{array}$ & $30 \%$ & $64 \%$ & $6 \%$ & & \\
\hline
\end{tabular}

Table 1: Students' perceptions of the learning experience. 


\section{The Students' Perspective}

\section{The Study}

The study investigated attitudes of Hong Kong students towards the significance of the Project experience. The students, enrolled in the Project subject, were surveyed after its completion. All the students were asked to complete a questionnaire; participation in the survey was voluntary. The students were asked to rate three aspects of the Project group context, project-based task, and outside focus. In addition, students were asked to indicate which of the three aspects of the Project they regarded as most important to their learning experience.

\section{The Findings}

Of the 160 students enrolled, 143 completed the survey. The students' perceptions of the impact of the individual aspects of the Project on their learning experience are shown in Table 1. A 5-point Likert scale was used, where 5 indicated strongly agree and $1 \mathrm{in}$ dicated strongly disagree. The results are reported as percentages on the Likert scale.

Students' evaluation of the three aspects of the Project in terms of importance to their learning experience is reported as percentages in Table 2 . The percentages indicate the proportion of students who regarded that aspect as most important of the three.

\begin{tabular}{|lc|}
\hline Aspect & $\begin{array}{l}\text { Most important } \\
\text { to \% of students }\end{array}$ \\
Group Context & $34 \%$ \\
Project-based Task & $46 \%$ \\
Outside Focus & $20 \%$ \\
\hline
\end{tabular}

Table 2: Importance to learning expen-

\section{Discussion}

Results of the survey indicated that Project is an important learning experience to the Hong Kong stu dents. Both group context and project-based task were regarded as equally important in terms of their contribution to the learning experience. Focus on communication planning and management skills, opportunity to apply knowledge and ideas to a specific task, as well as opportunity to control one's learning were singled out as most important characteristics. Although the outside focus was acknowledged as providing benefits, students did not rate these benefits as highly as those associated with project-based task and group context. While the relative ranking of the individual aspects of the Project model revealed that the group context was highly regarded, the project-based task was clearly valued highest, and outside focus ranked significantly lower than the other aspects.

A comment on lessons learnt and benefits gained from the Project included in one of the reports seems to confirm the survey findings:

Very importantly, we experienced teamwork while developing the project. Developing the system was no easy task. Time was short, while problems surfaced from time to time. Through cooperation, we solved the problems one by one, and managed to complete the system within the time limit. Developing the system was a valuable experience for each of us, and we will apply what we have learned in our work.

\section{Conclusions}

Project is an important subject in the computer science degree, and the success of its transnational offering was thus largely dependent on the successful implementation of the Project model in Hong Kong. Several factors were seen as potential impediments to such success - common analyses of cultural approaches to learning were not conducive to optimism, and constraints on learning imposed by time and mentoring support were less than desirable. Nonetheless, students appear to have responded favorably to 


\section{Transnational Education through Engagement}

the Project model, and regarded its challenges as matters to be addressed in the completion of the Project. This attitude was reflected in the responses to the survey, and confirmed by the comments students have made in their final Project reports.

Although further research is needed to explore students' reaction in more detail, preliminary results have been supportive of the Project approach, especially its project-based task and group context. One aspect of this research was to measure Hong Kong students' perceptions of the Project. The results would appear to confirm that students have accepted Project as a useful and valuable learning experience.

The second aspect of this research was to investigate the appropriateness of engagement theory as a paradigm to underpin the Project model. Students' reluctance to confirm the importance of the outside focus may indicate that they do not regard this as essential to an effective learning experience. This may relate to their background as they are all in full-time employment, and already work in a real-world environment. However, it may also mean that the difficulties associated with securing an external project, communicating with clients, and meeting additional require ments outweigh, in students' opinion, the benefits of a 'big-computing' experience. This issue requires further investigation as, based on the current results, it may also mean that engagement theory might have over-emphasized the importance of outside focus.

Further research is intended to explore the suitability and importance of Engagement Theory in other subjects of the course, for example Software Engineering, which, although not solely project-based, includes a substantial project component. In addition, a study is in progress to compare the perceptions of Project students in Melbourne and in Hong Kong.

\section{References}

Biggs, J.B. (1997). Teaching across and within cultures: the issue of international students. In Murray-Harvey, R. \& Silins, H.C. (Eds.) Learning and Teaching in Higher Education: Advancing International Perspectives, Proceedings of the Higher Education Research and Development Society of Australasia Conference, Adelaide: HERDSA, 1-22.

Bullock, J.F. (1998). Internet technologies for enterprise development and learning. ALN Magazine, 2(1). Retrieved December 2001, from http://www.aln.org/alnweb/magazine/vol2 issue1/bullock.htm

Chickering, A.W., \& Ehrmann, S.C. (1996). Implementing the seven principles: technology as lever. AAHE Bulletin, 49(2).

Chickering, A., \& Gamson, Z. (1987) Seven Principles of Good Practice in Undergraduate Education. AAHE Bulletin, March.

Churcher, N., \& Cockburn, A. (1997). An immersion model for software engineering projects. Proceedings of the Second Australasian Conference on Computer Science Education, Melbourne.

Cohen, E. (1999). Reconcepualizing information systems as a field of the transdiscipline informing science: from ugly duckling to swan. Journal of Computing and Information Technology. 7(3), 213 -219. Retrieved December 2001, from http://www.is2002.com/WhatIS.htm

Dede, C. (1996). Distance learning to distributed learning: making the transition. Learning \& Leading with Technology, 23(7). Retrieved December 2001, from http://www.educause.edu/nlii/articles/dede.html

Dolmans, D. (1992). The relationship between student-generated learning issues and self-study in problem-based learning. Instructional Science, 22(4), 251-267.

Fairchild, G.F., \& Taylor, T.G. (2000). Business Simulations and Issue Debates to Facilitate Synthesis in Agribusiness Capstone Courses. Retrieved September 2002, from http://bear.cba.ufl.edu/centers/ciber/workingpapers/capstone.pdf

Felder, R., \& Brent, R. (1996). Navigating the bumpy road to student-centred instruction. College Teaching, 44(2), 43-47.

Fogarty, R. (1997). Problem-Based Learning and Other Curriculum Models for the Multiple Intelligences Classroom. ERIC Document No. ED405143.

Idrus, R. (1993). Collaborative learning through teletutorials. British Journal of Educational Technology, 24(3), $179-184$.

Kearsley, G., \& Shneiderman, B. (1999). Engagement Theory: A framework for technology-based teaching and learning. Retrieved July 2002, from http://home.sprynet.com/ gkearsley/engage.htm 
Kelly, M.E., \& Tak, S.H. (1998). Borderless education and teaching and learning cultures: the case of Hong Kong. Australian Universities' Review, 41(1), 26-33.

Kember, D. (1998). The Learning Experience of Asian Students: A Challenge to Widely-held Beliefs. Plenary Address given at the $12^{\text {th }}$ Annual Conference of the Asian Association of Open Universities, Hong Kong.

Kember, R., \& Gow, L. (1991). A challenge to the anecdotal stereotype of the Asian student. Studies in Higher Education, 16(2), 117-128.

Kingsland, A. (1996). Time expenditure, workload, and student satisfaction in problem-based learning. In Wilkerson, L. \& Gijselaers, W.H. (Eds.) Bringing Problem-Based Learning to Higher Education: Theory and Practice. (pp.73-81). San Francisco: Jossey-bass Publishers.

Magney, J. (1996). Preparing Technicians for the Management of Technology. ATEA Journal, 23(4), 8-11.

Novitzki, J.E. (1998). The MIS Capstone: Development of an Integrating Group Applied Project Course. In Proceedings of the International Academy for Information Management (IAIM) $13^{\text {th }}$ Annual Conference (pp.100-109). Helsinki, Finland.

Robinson, B. (1998). Asian learners, Western models: Some discontinuities and issues for distance learners. Proceedings of the $12^{\text {th }}$ Annual Conference of the Asian Association of Open Universities. Part III, (pp.370-375). Hong Kong: The Open University of Hong Kong.

Schiller, J., Ostwald, M., \& Chen, S. (1994). Implementing a problem-based, distance education undergraduate course in construction management. Distance Education, 15(2), 300-317.

\section{Biography}

Iwona Miliszewska and John Horwood are both senior lecturers in computer science at Victoria University. They have contributed to the administration and teaching of the transnational program in Hong Kong. They have cooperated in research projects involving distance education, lifelong learning and women in computer science, and have published in these areas.

Albert McGill is Dean of the Faculty of Science, Engineering and Technology and Professor of Analytical and Food Chemistry. The computer science program in Hong Kong is delivered by and administered from the Faculty. His research interests in education range from distance and open education through research training options to factors affecting staff attitudes and behavior in all of which he is an active participant. 